\title{
A Multi-Agent (MA) Cellular Automaton (CA) Framework for Grapevine Growth and Crop Simulation
}

\author{
S. Shanmuganathan Senior Member, IACSIT, A. Narayanan, and N. Robinson
}

\begin{abstract}
A multi-agent (MA) cellular automaton (CA) model framework for simulating grapevine growth and crop in Chardonnay cultivated in northern New Zealand is presented. Estimating or projecting grape crop in quantity (grapes in tons per hectare (ha)) and berry quality in Brix (sugar content) is an extremely complex and challenging task. The crop depends on many factors, such as local weather and environmental conditions that interact with each other at varying degrees and over different time intervals in a "chaotic" manner. The key factors and their influences are simulated using CA rules, MA behaviour and interactions. Two sets of CA lattices and rules are used to simulate individual grapevine growth and vineyard phenological dynamics respectively. The results achieved show potential for simulating vine growth and yield in different grape varieties (Pinot Noir, Pinot Gris, Merlot and other wine styles) and scales, such as New Zealand's major wine regions and that of the world's, in ways not been explored previously.
\end{abstract}

Index Terms—Component; climate effects; yield; vineyard.

\section{INTRODUCTION}

Obtaining an accurate estimation of grapes in quantity (i.e., tons/ha) and quality (sugar, aroma and other colour phenol contents) is an extremely complicated task, yet it has operational and economic significance to viticulturists and vintners (1) (2). Traditionally, vineyard yield and must composition are measured in terms of tons per hectare (ha) and Brix (and some occasions with $\mathrm{pH}$ and acidity) respectively. Over the years, there have been formulae developed to estimate the crop using vines/ha, clusters/vine, buds/vine and cluster/ berry weight values (sampled averages) for different varieties and the paper gives an outline on some basic formulae currently in use. Meanwhile, in any approach inconsistencies between a vineyard's estimated and real crop figures are attributed to the following two factors;

(1) $70 \%$ of the variation from year-to-year variability in the number of clusters and

(ii) $30 \%$ of it from the variability in cluster weight.

From the initial introduction of Van Neumann neighbourhood rules in the 1950s (3) (4) to recent satellite imagery grid quantification research (5), there have been significant advances in the development and application of CA and other related hybrid approaches to simulating spatial

Manuscript received May 30, 2012; revised July 27, 2012.

Subana Shanmuganathan is with Geoinformatics Research Centre, Auckland University of Technology, Private Bag 92006, Auckland 1142, New Zealand. (e-mail: subana.shanmuganathan@aut.ac.nz ).

Ajit Narayanan and Nick Robinson are with School Computing and Mathematical Sciences, Auckland University of Technology, Private Bag 92006, Auckland 1142, New Zealand (e-mail: ajit.narayana@aut.ac.nz). and temporal changes in a wide spectrum of disciplines. The second section of the paper briefly outlines a few CA frameworks specially developed for vegetation dynamics simulation. Consequently, details of a multi-agent CA framework being developed for simulating grapevine growth and yield in Chardonnay cultivated in northern New Zealand are presented.

\section{CROP EstimAtion IsSUES IN ViticUltuRE}

Adverse consequences of inaccurate grape crop estimation and related issues are well-known among viticulturists and vintners all over the world, and this has led to increased demand for improved techniques to better estimate the crop (6). Currently used conventional methods are:

(i) destructively harvesting whole vines or segments of vines or

(ii) randomly sampling and weighing bunches and then combining these with bunch counts.

Both methods require adequate sampling and data interpretation for accurate crop estimation. However, vineyard management is seen to be understandably unwilling to commit sufficient resources during the busy harvest season. This unwillingness to allocate more resources during this time for proper sampling is a major impediment with these conventional methods. The present situation clearly indicates that there is a pressing need for less demanding methods in terms of resources for crop forecasting.

\section{A. Conventional Methods of Crop Estimation}

This is the more common one of the three conventional crop estimation methods and is based on formula (1).

$$
\begin{aligned}
& \mathrm{PY}=(\text { ANV } \times \text { NC } \times \text { CW) } / 2000 \\
& \text { where, } \\
& \text { PY = predicted yield (tons/ acre }) \\
& \text { ANV = actual number of vines / acre } \\
& \text { NC = number of clusters/ vine } \\
& \mathrm{CW}=\text { cluster weight (in pounds) } \\
& 2000 \text { =rough conversion of pounds to ton }
\end{aligned}
$$

\section{B. Lag Phase Method}

This method uses cluster weights collected during the "lag phase", which refers to a period when seeds begin to harden and this occurs about 55 days after first bloom or corresponds to the accumulation of $1000-1300$ growing degree days (GDD) or heat units. During this period berry growth slows down temporarily and it is considered that at this lag phase the berries have reached about $50 \%$ of their final weight. Based on this theory, the cluster weight at harvest can be 
predicted by multiplying the lag phase weight by an "increase factor" of 2 as in formula (2). However, the multiplier varies depending on the variety and season hence vineyard managers are advised to determine their own multipliers for each variety/ vineyard. Furthermore, GDD required for calculation with the lag formula can be obtained from any nearby meteorological station. The formula used for this method is as follows:

$$
\begin{aligned}
& \mathrm{PY}=(\mathrm{ANV} \times \mathrm{NC} \times \mathrm{Lag} \text { CW } \mathrm{x} \text { 2) } / 2000 \\
& \text { where, } \\
& \begin{array}{ll}
\mathrm{PY} & =\text { predicted yield (tons/ acre) } \\
\mathrm{ANV} \quad=\text { actual number of vines } / \text { acre } \\
\mathrm{NC} \quad=\text { number of clusters/ vine } \\
\mathrm{Lag} \mathrm{CW} & =\text { cluster weight at lag phase (in pounds) }
\end{array}
\end{aligned}
$$

\section{More Elaborative Method}

This method includes average values for all possible variations from vine/ ha down to berry weight, as stated in (7).

Predicted yield = (vines / ha) $\mathrm{x}$ (buds / vine) $\mathrm{x}$ ( shoots/ bud) $\mathrm{x}$ (bunches / shoot) $\mathrm{x}$ (berries / bunch) $\mathrm{x}$ berry weight.

\section{CA FRAMEWORK IN VEGETATION DYNAMICS SIMULATION}

CA framework designs developed and implemented for vegetation dynamics simulation over the last six decades continue to gain popularity due to their ability to provide previously unknown new information on the likely patterns in the spatiotemporal changes of complex natural habitats. Increasingly, the new knowledge gained using CA models is described as detailed enough for management decision making in certain specific problem domains. Spatial patterns and trends over time in the dynamics of forest tree population (8), alpine tundra vegetation (9), rain forest species composition (10) and weed population (11) are among some useful simulations in this specific domain. The publications (8)-(10) describe how CA rules relating to a micro scale, i.e. individual plant, could be applied to simulate changes at meso/ macro scales influenced by different factors and at varying degrees, i.e., field under current and future scenarios as discussed below.

In (12) the authors simulated the effects of future climate change scenarios under different greenhouse gas emissions and then estimated future irrigation requirements for vineyards in Spain by combining global circulation and crop models. The scenarios for different greenhouse gas emissions were produced by perturbing the water generator based on a Canadian climate change model (CGCM2) results for selected areas studied in the north east corner of the Iberian Peninsula. The "LARS-WG" weather generator was run with historical data covering a 42 year period to generate some 100 possible local weather scenarios corresponding to years 2010, 2015 and 2025 for the simulation. In addition, CropSyst was used to simulate vineyard water balance. The crop simulation for 2005 reflected the FAO-56 ${ }^{1}$ crop co-efficiencies and even though the weather model suggested early spring and hastened harvest, interestingly this was concluded to be causing lesser burden on future irrigation requirements than earlier anticipated. Literature reviewed for this research reveals a paucity on examples of how CA can simulate vine growth on a temporally regular basis (e.g. hours, days), taking into account of realistic and actual changes in weather data. Such CA simulations can provide a means for model testing, fitting as well as yield prediction purposes under real and future potential weather change scenarios. They could enhance modeller ability to predict yields using real weather conditions of a grapevine's growth cycles and under different vine management strategies for potential /target /actual yield.

\section{Multi-AgENT CA FrameWORK FOR SimUlATING GRAPEVINE GROWTH AND CROP}

This section presents details of a multi-agent CA framework with two different sets of lattices and rules for simulating an individual vine growth of Chardonnay grape and yield in a vineyard.

At this initial investigation, an individual vine growth is divided into 1) budburst, 2) leaf growth, 3) clusters of inflorescence initiation, 4) flowering, 5) berry formation, 6) development and 7) ripening stages, and simulated using a $1 \mathrm{x}$ $\mathrm{l}$ set of lattice and individual vine growth rules. In this vine simulation, major growth factors (soil quality, water stress and exposure to solar radiation) and triggers, (daily maximum, minimum and soil minimum temperatures as well as GDD) are used to calculate a variable called "available energy” (AE), the driving force for vine growth (Fig. 1).

The AE calculated using formula (3) and (4) is in turn utilised for growth in five vine organs, namely trunk, bud, shoot, leaf and cluster, depending on the "stage" of the vine growth (1-7). A term "priority" is used to define the growth stage in the vine CA cycle. In modern day viticulture, annual grapevine growth cycle is divided into seven growth stages (also used in this study) based on temperature/day length/ growing degree days (GDD/ heat units) hence, temperature and GDD are used in the vine CA cycle to define the priority and stage. Any excess Energy not used in the current cycle will be stored in trunk as Stored Energy (SE).

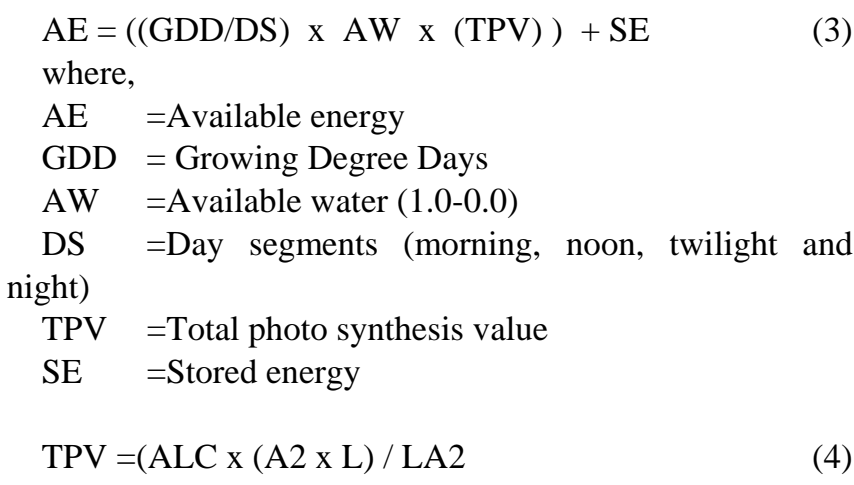

\footnotetext{
${ }^{1}$ Even though 56 (FAO-56) co-efficient is expected to provide a universally consistent methodology for obtaining reliable estimates of crop evapotranspiration it has its own limitations (13)
} 
where,

ALC =Active leaf cover in cell

CA2 =Cell area 2 (in centimetre2)

$\mathrm{L} \quad=$ Light $(1.0-0.0)$

Cells =Cells in grid

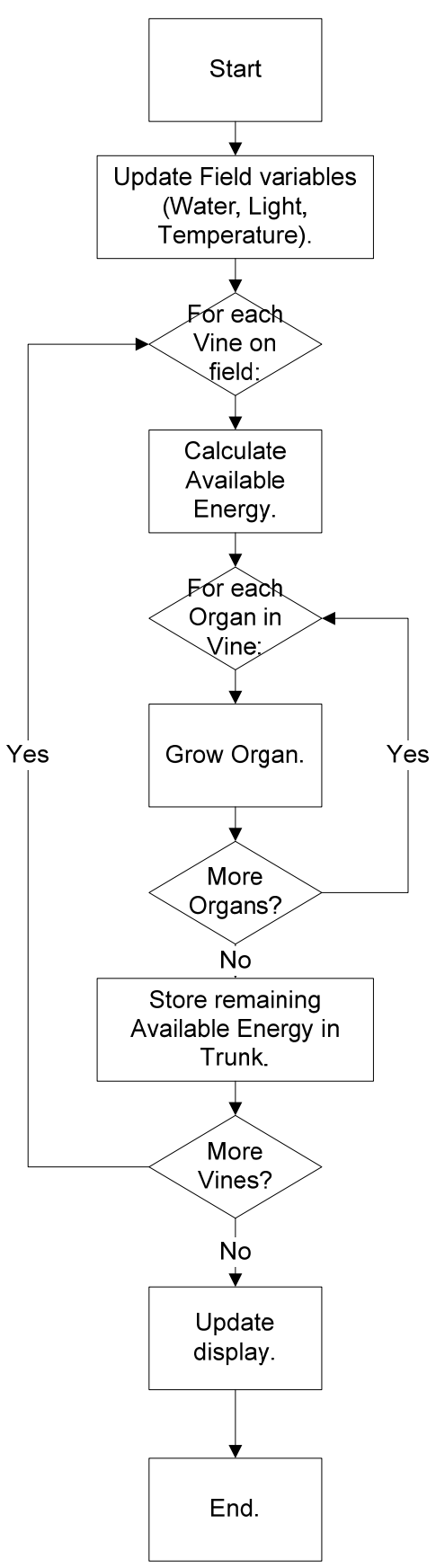

Fig. 1. Schematic representation of the main processes relating to individual vine CA cycle. Each vine growth is displayed by a set of $1 \mathrm{x} l$ lattice cells simulated by vine rules.

Vine organ initiation, growth, maturity and death vary based on the type of organ and are simulated using rules in the vine CA cycle. For example, organ "leaf" grows into a full leaf after unfolding from a "shoot". The leaf growth continues until it reaches maximum leaf blade length, stays alive for several weeks producing energy via photosynthesis and then eventually dies off. Similarly, each organ has its own growth phases and rules in the vine CA cycle (see Fig. 3 for bud growth rules).

\section{A. CA Lattice for Grape Crop (Field) Simulation}

The grape crop simulation (field CA) displayed on a L x L set of lattice has its own set of rules. The field CA rules are applied to selected key parameters from the vine simulation along with environmental parameters whereby yield and related outcome/s at larger scales i.e., within a vineyard, are simulated. The key vine parameters used in the CA cycle are: vine canopy structure (buds/vine, clusters/vine, cluster weight). Random values are generated for environmental factors, such as soil quality, availability of water, solar radiation, temperature and humidity, to generate for "within-field" variability for the field CA cycle. Finally, the vineyard operations and results produced based on CA rules are displayed at different time intervals set by the user (Fig.2).

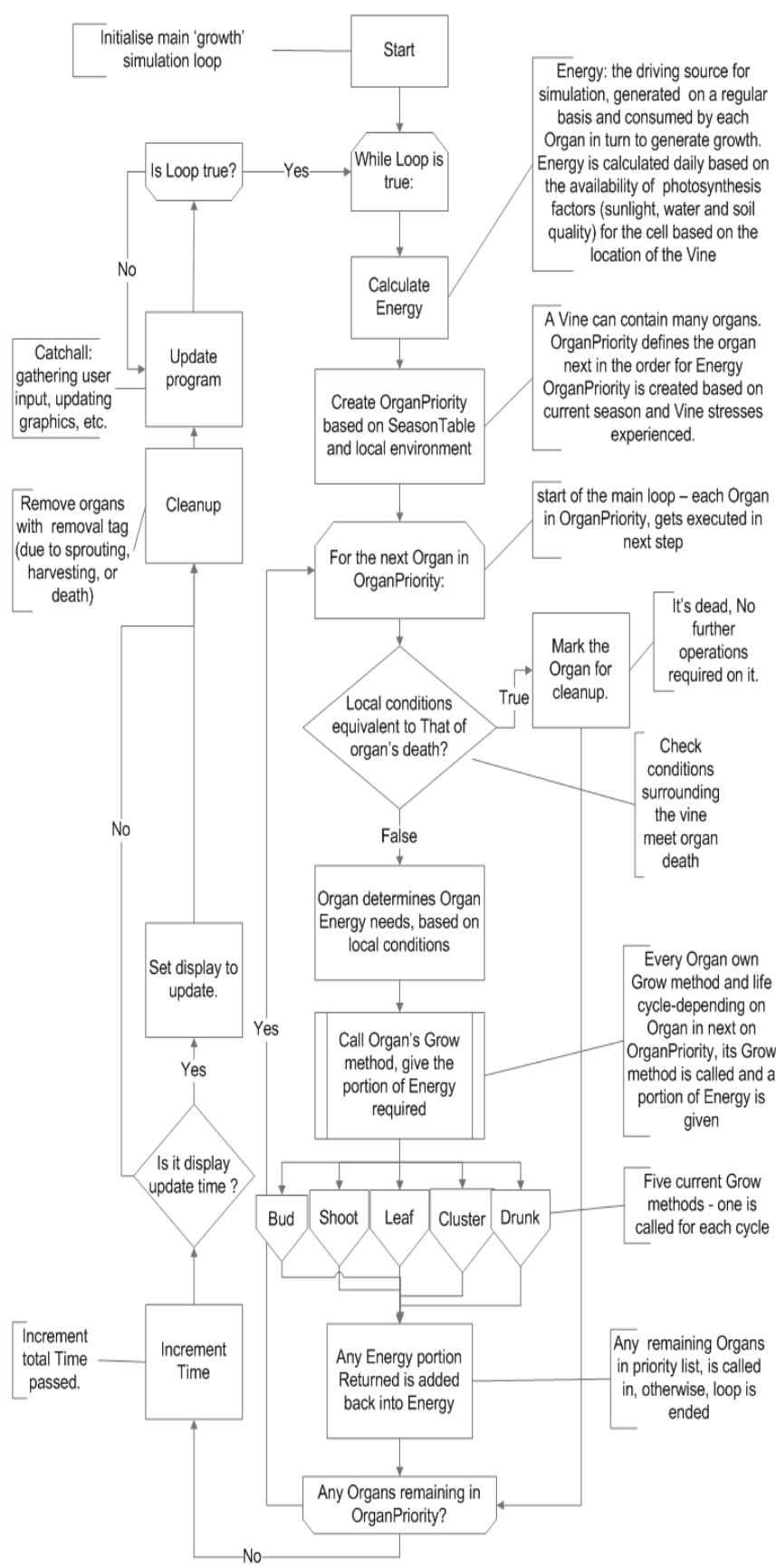

Fig. 2. Schematic representation of the main processes on the crop simulation cycle displayed by $\mathrm{L}$ x L lattice cells based on vineyard rules. 


\section{B. Agents for Vineyard Management Operations}

Vineyard management operations, such as pruning, fertiliser application, spraying (pesticide/fungicide), irrigation and harvest are incorporated through agents. The agent rules are used for implementing the vineyard operations and to define their potential outcomes; loss of foliage, nutrient increase.

\section{RESUlts}

The initial results of this multi-agent CA framework for simulating perennial crop (Figs 3-6) show how grape crop simulation at meso/ macro scales, such as a vineyard, could be achieved using expertise represented by rules, and available data on factors pertaining to micro scale issues (individual vine growth).

\section{All Organs \\ Variables: \\ Death Threshold $=0 \mathrm{oC}$}

Standard Organ death rule:

IF Local Temperature $<$ Death Threshold

Organ is dead.

\section{Bud rules}

Variables:

Frost Threshold $=2$ degrees centigrade.

Flower Daylength Threshold $=12$ hours

Flower Temp Threshold $=10$ degrees centigrade

Death:

IF Local Temperature $<$ Frost Threshold

Decrement Remaining Buds

IF Remaining Buds $==0$

Bud is dead

ELSE IF Local Temperature $<$ Death Threshold

Bud is dead.

\section{Growth:}

Add Growth to Total Growth

IF Total Growth >= Burst Threshold

IF Day Length > Flower Daylength Threshold AND Local Temperature $>$ Flower Temp Threshold

Bud is dead

Cause Vine to spawn new Shoot at Bud's location.

Remove any excess Total Growth beyond Burst Threshold, return to Growth

Return any remaining Growth

Fig. 3. Field CA rules for budburst, death and growth.

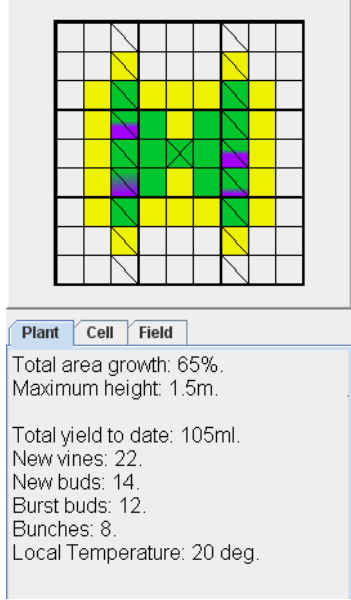

Fig. 4 . CA simulation showing vine growth with various grapevine organs that are incorporated in the vine CA cycle.

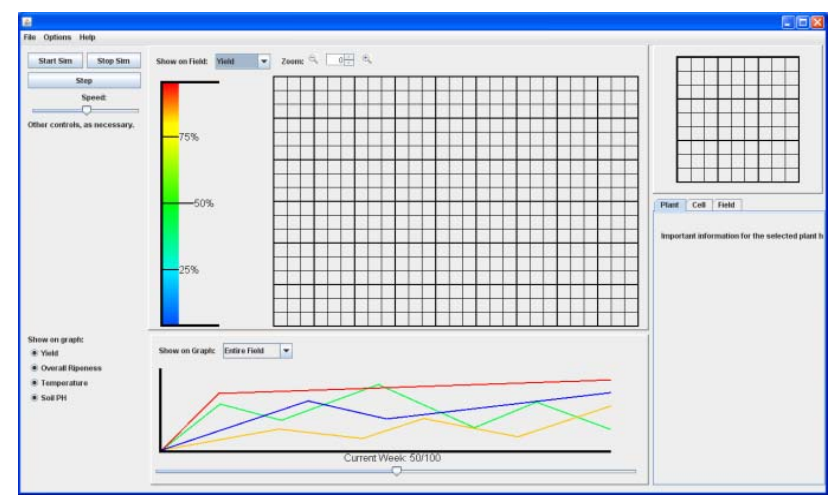

Fig. 5. CA simulation of grape vine growth and yield at larger scales, such as a vineyard or region. By changing the vine and field parameters it is possible to simulate growth and yield in diffident grapevine varieties, such as Chardonnay, Pinot Noir and Pinot Gris.

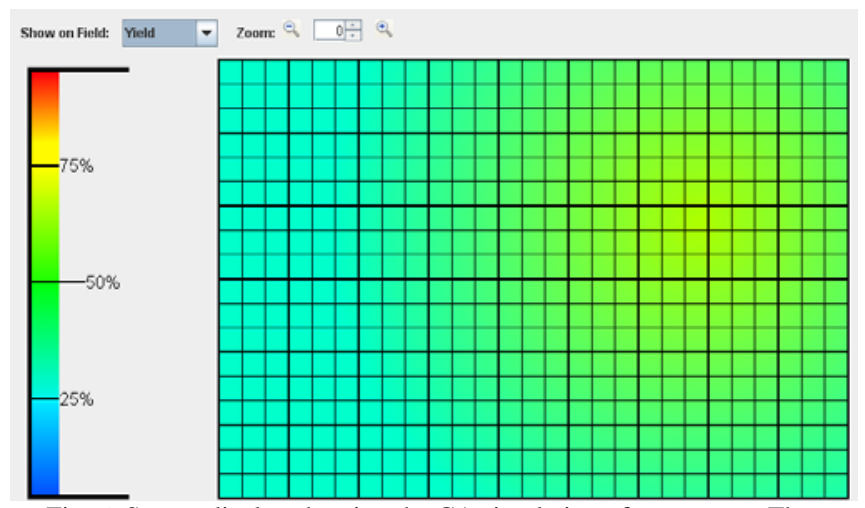

Fig. 6. Screen display showing the CA simulation of grape crop. The variability in yield within a vineyard is simulated based on variations generated in soil, availability of water, nutrients, solar radiation, temperature and humidity created with random number generators.

The vine CA lattice simulates growth in vine organs (as explained in Section 4) beginning with budburst, leaves, clusters (fluoresce and berry) to produce grapes for both, in a vine (in berry weigh and berries/ cluster) and in a vineyard (in terms of grapes (tons/ha), Brix, $\mathrm{pH}$ and acidity). The user interface has buttons, tabs and scroll bars to set/ change critical parameters relating to individual vine growth, such as buds/ shoot, shoots/ vine, clusters/ shoot, berries/ cluster and berry size. These parameters could be used to change values based on the grape variety being simulated.

\section{CONCLUSIONS}

The paper described the initial investigation so far conducted on simulating vine growth and vineyard yield in Chardonnay cultivated in northern New Zealand. Even without the vineyard operations designed for inclusion as multi-agents, the preliminary results of CA simulations (vine and field) are promising. It is believed that on full implementation of the multi-agent based CA framework with an interface, the approach will enhance viticulturists' ability to better predict their outcomes under different scenarios, such as pruning decisions, number of buds/ shoot to allow for full growth for that season, under future climate change and at different scales. The major benefit with the approach is that it provides an alternative method to estimating yield without incurring any additional cost, as this approach can be simulated with historic and other model prediction data. As 
far as we are aware, this is the first attempt to contribute to 'precision viticulture' (14) through the use of cellular automata that take into account detailed information concerning both resources (energy, water) as well as important botanical features (leaves, buds, etc). Finally, with the inclusion of a wine quality module vintage ratings as well could be predicted under different possible weather and other atmospheric conditions.

\section{ACKNOWLEDGEMENTS}

The authors wish to thank Michel Brajkovich Master of wine, Kumeu River Wines. Prof Philip Sallis and Peter Sumich of AUT are acknowledged for their continuous support.

\section{REFERENCES}

[1] Imed. Dami, Methods of Crop Estimation in Grapes. [Online] 2010. [Cited: 279 2010.]

www.oardc.ohio-state.edu/grapeweb/OGEN/07262006/CropEstimatio n06.pdf.

[2] Mike Trought, Yield Management and Prediction. http://www.wineresearch.org.nz/. [Online] Marlborough Wine Research Centre, 2009. [Online]. Available: www.wineresearch.org.nz/projects/SR06-01aYieldManagmentPredict ion.pdf.

[3] S. Bandini, G. Mauri, and R. Serra, 2001 Cellular automata: From a theoretical parallel computational model to its application to complex systems. www.elsevier.com/locate/parco, 2001, vol. Parallel Computing 27 (2001) 539-553.

[4] S. Geertman, M. Hagoort, and H. Ottens, 2007 Spatial-temporal specific neighbourhood rules for cellular automata land-use modelling. 21: 5 547-568, London, UK: Publisher Taylor \& Francis, 2007, Vol. International Journal of Geographical Information Science.

[5] M. Espínola, R. Ayala, and Saturnino Leguizamón, 2008 Classification of Satellite Images Using the Cellular Automata Approach [Eds] M.D.
Lytras et al. Springer-Verlag Berlin Heidelberg, 2008, The Open Knowledge Society. A Computer Science and Information Systems Manifesto Communications in Computer and Information Science, 2008, vol. 19, 521-526, DOI: 10.1007/978-3-540-87783-7_66.

[6] Gregory M Dunn and Stephen R Martin. 2004 Yield prediction from digital image analysis: A technique with potential for vineyard assessments prior to harvest. Australian Journal of Grape and Wine Research 10, pp196-198.

[7] M. Keller, J. M. Tarara, and L. J. Mills, 2010 Spring temperatures alter reproductive development in grapevines_105. Wiley Online Library, 2010, Australian Journal of Grape and Wine Research vol. 16, 445-454, 2010.

[8] G. Stamatellos and G. Panourgias, 2005 Simulating spatial distributions of forest trees by using data from fixed area plots. Institute of Chartered Foresters, 2005, vol. Forestry, vol. 78, no. 3, 2005. forestry.oxfordjournals.org doi:10.1093/forestry/cpi028.

[9] A Yanqing Zhang, et al. 2008 Cellular Automata: Simulating Alpine Tundra Vegetation Dynamics in Response to Global Warming. Arctic, Antarctic, and Alpine Research vol. 40, no. 1 / February 2008 pp. 256-263.

[10] David Alonso, and Richard V. Sole', 2000 The DivGame Simulator: a stochastic cellular automata model of rainforest dynamics. Ecological Modelling 133 (2000) 131-141.

[11] A. Y. Zhang, M. R Peterman, D. L., Aunand and Y Zhang, 2003 Using CA model to obtain insight into mechanism of plant population spread in a controllable system: annual weeds as an example. Ecological Modelling 166 (2003) 277-286.

[12] Jordi Marsal, and Angel Utset. Vineyard Full Irrigation Requirements under Climate Change Scenarios for Ebro Valley, Spain. [book auth.] Valladolid, Spain) Angel Utset (ITACyL. Climate Variability, Modeling Tools and Agricultural Decision-Making 978-1-60692-703-8 261 pages. Nova Publishers, 2009, pp. 119-126.

[13] D. J. Hunsaker, P. J. Pinter, and H. Cai, Alfalfa basal crop coefficients for FAO-56 procedures in the desert regions of the southwestern U.S. [Online] 2002. ISSN 0001-2351.

[14] S. Best, L. León and M. Claret. 2005. Use of precision viticulture tools to optimize the harvest of high quality grapes. Information and Technology for Sustainable Fruit and Vegetable Production (FRUTIC 05), 249-258,.S. Chen, B. Mulgrew, and P. M. Grant, “A clustering technique for digital communications channel equalization using radia basis function networks," IEEE Trans. on Neural Networks, vol. 4, pp. 570-578, July 1993. 